\title{
Comment
}

\section{Nearly five centuries of science books}

\author{
Daniele Gouthier
}

\begin{abstract}
In four steps - from Renaissance to the dawn of the $20^{\text {th }}$ century - this issue explores some aspects of the history of book sciences, as research and popularisation instruments also playing a role in economy. Adrian Johns speaks about the origin of science books in the Renaissance. Then, through the papers respectively by Bruce Lewenstein and Paola Govoni, the focus moves to science books in $19^{\text {th }}$-century America and Italy. They demonstrate that, in both countries, science books were a stimulus to the establishment of a national scientific community. Finally, Francesco De Ceglia exemplifies the role played by agrarian catechisms in the process of spreading farming skills among landowners.
\end{abstract}

In the history of the past few centuries, science books acted as instruments of research and science popularisation. They aroused incidents and opened new frontiers. However, they also consolidated knowledge by spreading it to non-experts. They innovated and created culture. And most of all, they played a crucial role in the course of the economy of the places where they were published and spread.

Often, innovation and culture did not have well-defined borders, as they mutually amplified their scope. In the Renaissance - the first of the four steps of this commentary, to quote Johns interviewed by Giovanni Blandino - "it is hard to draw a boundary between culture and scientific books." Writings such as Copernicus's were a revolution to the meaning itself of the humanity concept. Humankind, together with the Earth, was flung into the centre of the Universe and this could not represent only some technical data. It immediately turned into a cultural element questioning all the intellectuals: the role of man was to be redesigned.

The great Renaissance science philosophers discussed issues arousing novel scenarios and questions that involved everybody. Then there were works which today would be defined as technical - for example about sailing - or pseudo-scientific and alchemical. Altogether, the picture was scarcely populated, with only a few outstanding works and a number of books that (when not following some beliefs uncritically) were aimed at improving the skills of technical professions such as agriculture.

In the $19^{\text {th }}$-century US, the situation was somehow more backward than in the European Renaissance: only a very limited number of science books were published, other than those translated or imported from Great Britain. In any case, they were addressed to people within a reference community: engineers wrote to fellow engineers, physicians to fellow physicians, and so on.

Interestingly enough, less than a century later, in the late $19^{\text {th }}$ century, two parallel movements were born, which led respectively to the publication of research science books and popularisation books. It was the effect of the birth of a national scientific community approaching society in a very open way, according to the belief that - as Lewenstein reminds us - "science and technology were contributing to the evolution of a new world." It was a sort of American Renaissance, sawing scientists talking to the rest of society, economists in particular: a few prominent scientists even started to act as science philosophy spreaders. They wanted everybody to make scientific experiences and try the scientific way.

Incidentally, these two intertwined movements produced popularisation works which turned out to be true milestones in the American scientific culture, edited and re-edited for many decades (a few up to the 1970s) and had an explicit and demonstrated effect on science careers. Many researchers have given these books credit for inspiring them to choose science as a profession.

In Italy, this tradition began a little later, only in the wake of the Reunification and of a reform of university which enabled the birth of new institutions (including the Polytechnic of Milan) which prompted Italian scientists to act as a scientific community. It was the last decade of the $19^{\text {th }}$ century. In 
this process - as Govoni highlights - popularisation books played an essential role, following the momentum of the "Science for All" movement launched in the UK in the thirties.

"For all" interpreted in the Italian way, since the vast majority of the population was illiterate: the first census in 1861 revealed that $75 \%$ of Italians were illiterate. In this context, the $3-5 \%$ share of Italians buying books purchased many science books: as much as $40 \%$ of the books edited in the late $19^{\text {th }}$ century were science, medicine or technology books. And popularisation books allowed Italian scientists to introduce themselves as interlocutors to politicians and entrepreneurs, to link their knowledge to social and economic enterprises.

This economic aspect leads us back again to the Renaissance origins of the subject, when the science book started to become a real economic opportunity. The industrial aspect of the production of (science) books was crucial from the very beginning: going from a manuscript to a printed book implied multiplying by thousands the number of published copies which could go round. This was an extraordinary cultural multiplier for scientific ideas and, not secondarily, it became a relevant economic opportunity, marking the creation of a new market. Books were printed and, when reaching new places, re-printed and possibly translated. The international trade routes turned into culture-spreading routes: trade centres also became cultural centres. Books also contributed to the birth of cultural centres other than cathedrals and universities. Culture started to spread into the courts and academies, the borders between the well-educated and the rest of the population started to change. Culture was then spread from the literates to the illiterates, marking a departure from dialogue between peers.

An example of this - illustrated by De Ceglia in the framework of Southern Italy - is the spreading of agrarian catechisms, obviously addressed to landowners rather than rude farmers. Catechisms have a dialogic style, expressed by questions and answers between two imaginary (omniscient) interlocutors. Their purpose was "spreading of information, often of an encyclopaedic nature." They were addressed to someone interested in learning, e.g. for professional reasons, but at the same time not having the time or the skills to invest in the learning process. So catechisms, through their repetitive dialogic style to be read many times, were meant to be memorised by those listening to their stories. This is science becoming a production tool, directly speaking to workers. Or rather, to those managing the work.

How TO CITE: $\quad$ D. Gouthier, Nearly five centuries of science books, Jcom 10(01) (2011) C01 